\title{
HOXA10 is associated with temozolomide resistance through regulation of the homologous recombinant DNA repair pathway in glioblastoma cell lines
}

\author{
Jin Wook Kim MD ${ }^{1, *}$, Ji Young Kim MS ${ }^{1, *}$, Ja Eun Kim ${ }^{1}$, Seung-Ki Kim ${ }^{1,2}$, Hyun-Tai \\ Chung ${ }^{1}$, and Chul-Kee Park ${ }^{1}$ \\ ${ }^{1}$ Department of Neurosurgery, Seoul National University College of Medicine, Seoul National University Hospital, Seoul, \\ Korea \\ 2 Division of Pediatric Neurosurgery, Pediatric Clinical Neuroscience Center, Seoul National University Children's Hospital, \\ Seoul, Korea; \\ * These authors contributed equally to this paper. \\ Correspondence to: Chul-Kee Park, email: nsckpark@snu.ac.kr \\ Keywords: HOXA 10, temozolomide resistance, homologous recombination, EGR 1, PTEN
}

Received: April 7, 2014

Accepted: June 25, 2014

Published: June 25, 2014

This is an open-access article distributed under the terms of the Creative Commons Attribution License, which permits unrestricted use, distribution, and reproduction in any medium, provided the original author and source are credited.

\section{ABSTRACT:}

Temozolomide resistance is associated with multiple DNA repair pathways. We investigated homeobox (HOX) genes for their role in temozolomide resistance, focusing on the homologous recombination (HR) pathway, and we tested their therapeutic implications in conjunction with $0^{6}$-methylguanine DNA methyltransferase (MGMT) status. Two glioblastoma cell lines with different MGMT statuses were used to test the augmented anticancer effect of temozolomide with HOXA10 inhibition. In vitro experiments, including gene expression studies with RNA interference, were performed to verify the related pathway dynamics. HOXA10 inhibition reinforced temozolomide sensitivity independent of MGMT status and was related to the impaired double-strand DNA breakage repair process resulting from the downregulation of Rad51 paralogs. Early growth response 1 (EGR1) and phosphatase and tensin homolog (PTEN) were the regulatory mediators between HOXA10 and the HR pathway. Moreover, HOXA10 inhibition selectively affected the nuclear function of PTEN without interfering with its cytoplasmic function of suppressing the phosphoinositide 3-kinase/Akt pathway. The mechanism of HR pathway regulation by HOXA10 harbors another target mechanism for overcoming temozolomide resistance in glioblastoma patients.

\section{INTRODUCTION}

Temozolomide has been a mainstay of chemotherapy for glioblastoma (GBM) for the past decade but still produces unsatisfactory clinical outcomes. Most GBM patients who are treated with standard therapy incorporating temozolomide eventually experience progression, and only $11 \%$ of patents remain progression free at 2 years [1]. The inescapable early treatment failure rate of standard treatment largely depends on temozolomide resistance. From the perspective of the drug mechanism of temozolomide, $\mathrm{O}^{6}$-methylguanine DNA methyltransferase (MGMT) has been proven to be associated with the prediction of the treatment effect [2]. However, there are further steps that lead the cancer cells to death after temozolomide treatment in relation to the DNA repair pathway, such as mismatch repair (MMR) and homologous recombination (HR) [3, 4]. Temozolomide cytotoxicity is initially mediated by the generation of $\mathrm{O}^{6}$-methylguanine from guanine, which can be repaired by MGMT [5]. However, unrepaired $\mathrm{O}^{6}$ - methylguanine successively results in thymine mispairing during DNA replication, and these mispairs result in futile cycles of the repair process by the MMR system due to the persistence of $\mathrm{O}^{6}$-methylguanine in the template strand [5]. These futile cycles of the DNA repair process eventually cause double-strand DNA breaks, leading to cell apoptosis if 
the HR system functions inadequately [5]. Therefore, temozolomide resistance can be induced if MGMT is activated, MMR function is defective, or HR is normal. In addition to the established mechanism of temozolomide resistance by MGMT, reports have been published concerning inactivating mutations of MSH6 among MMR genes contributing to temozolomide resistance in GBM [6-8]. However, the incidence of MMR alterations in GBM is infrequent; thus, it is considered to be less important for temozolomide resistance $[3,9]$. Otherwise, the contribution of HR to temozolomide resistance has been rarely studied, and little is known. We investigated temozolomide resistance and mechanisms to restore temozolomide sensitivity, focusing simultaneously on MGMT and HR.

To identify plausible targets for temozolomide resistance, we considered homeobox (HOX) genes, which showed a significant relationship between its dichotomized sub-classification with MGMT and survival in gene expression profiling studies, as previously reported [10]. HOX genes are a group of essential regulatory genes that normally control embryonic development and that should be in the silenced state in the adult central nervous system [11-13]. Recent studies have shown evidence of the aberrant expression of HOX genes in diverse cancers, including gliomas [14-18]. Although solid evidence exists concerning the role of HOX genes in oncogenesis and therapeutic resistance in gliomas, the exact mechanism remains unclear, and only a small number of recent studies have been published $[9,10,18]$. In the present study, we investigated the mechanism of HOXA10 regarding its role in temozolomide resistance using glioblastoma cell lines and tested the therapeutic implication of temozolomide resistance in conjunction with MGMT status. The result of the present study suggests a possible hypothesis for the temozolomide non-responders in MGMT-inactive GBM patients.

\section{RESULTS}

\section{HOXA10 mediates temozolomide resistance independent of MGMT}

The MGMT methylation status of the LN18 and LN229 glioma cell lines as measured by MSP revealed an unmethylated MGMT promoter (MGMT active) for LN18 cells and a methylated MGMT promoter (MGMT inactive) for LN229 cells (Figure 1A). Both cell lines displayed intact HOXA10 expression, which was successfully knocked down with iHOXA10. When the cell lines were treated with $\mathrm{TMZ}$ in combination with $\mathrm{O}^{6}-\mathrm{BG}$ and/or iHOXA10, significant differences in the cell death ratio were observed when iHOXA10 was added (Figure 1B). This additive effect of $\mathrm{iHOXA10}$ on cell viability was independent of the MGMT status and created an added effect over MGMT inhibition.

\section{Screening for effectors of HOXA10}

To identify HOXA10-regulated genes, we transduced LN18 cells with control siRNA or HOXA10silencing siRNA (iHOXA10) and carried out microarray gene expression profiling. We compared the expression values of selected probe sets displaying average foldchanges of at least 2.0-fold, yielding 124 probe sets as being differentially expressed (15 up- and 109 downregulated). Among them, only selected genes with RefSeq identifiers (NCBI Reference Sequence Database; http:// www.ncbi.nlm.nih.gov/refseq/) are listed (Table 2). We then used the functional annotation tools within DAVID Bioinformatics Resources (http://david.abcc.ncifcrf.gov/ home.jsp) to perform gene annotation enrichment [19]. This analysis indicated that early growth response protein 1 (EGR1) is a mediator for the functional category of transcription/cell division and chromosome partitioning among the listed genes. EGR1 showed a -3.09-fold change after iHOXA10 treatment. After thorough review of the functions of EGR1, we focused on previous reports indicating that EGR1 induces phosphatase and tensin homolog (PTEN) by regulating its promoter [20-22]. Moreover, evidence has shown that PTEN has novel nuclear functions, including transcriptional regulation of the Rad51 gene, whose product is essential for HR repair of DNA breaks $[23,24]$. Therefore, we hypothesized that

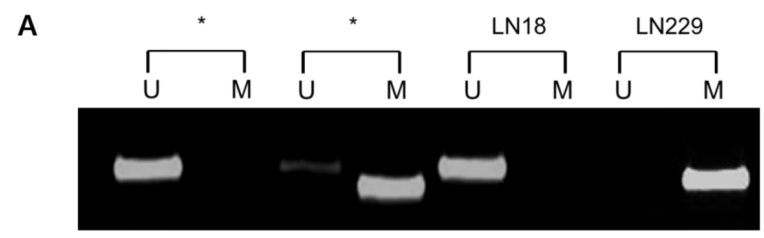

B

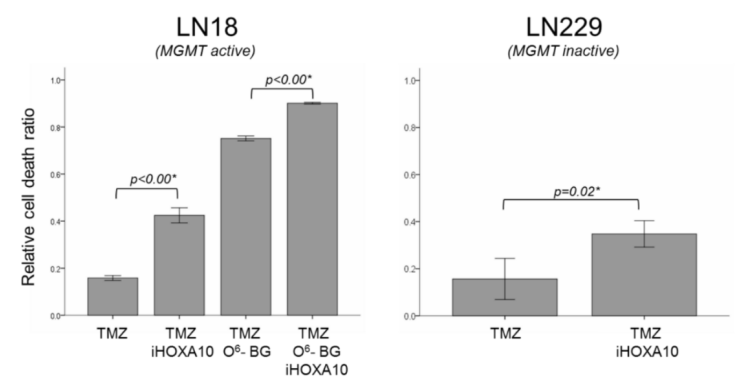

Figure 1: A. MGMT promoter methylation-specific polymerase chain reaction results. Each lane with an asterisk indicates control DNA for no methylation and methylation. The MGMT promoter is unmethylated in LN18 cells and methylated in LN229 cells. B. Cell viability results presented as the relative cell death ratio. Inhibition of HOXA10 shows an additive effect with temozolomide treatment in both cell lines, even after the inhibition of MGMT in LN18 cells. 
HOXA10 can regulate the HR system mediated by EGR1 and PTEN.

\section{HOXA10 selectively regulates the nuclear function of PTEN through EGR1}

After knockdown with iHOXA10, RT-PCR data showed significant suppression of EGR1 and PTEN in both LN18 (93\% and 30\% suppression) and LN229 (25\% and 58\% suppression) cells (Figure 2A). These results suggested that EGR1 and PTEN are the mediators regulated by HOXA10 status. However, suppression of PTEN induced by iHOXA10 did not affect the phosphoinositide 3-kinase (PI3K) pathway. The protein expression of total Akt and phosphorylated Akt showed no change, although PTEN was suppressed by iHOXA10 (Figure 2B). This finding implies that HOXA10 regulates
A

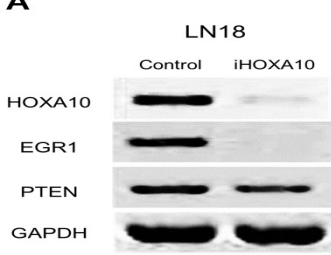

B

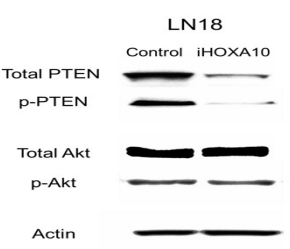

C

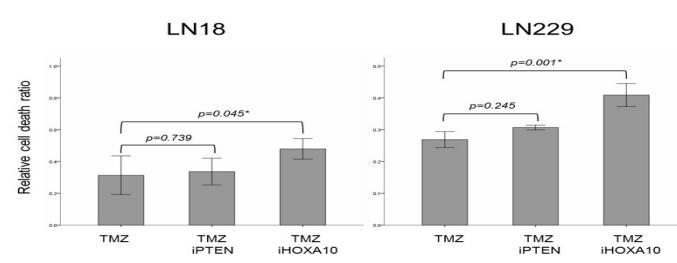

Figure 2: A. RT-PCR results after HOXA10 knockdown by siRNA. Reduced expression of EGR1 and PTEN is shown. B. Western blotting results after HOXA10 knockdown by siRNA. Despite the suppression of PTEN, the expression of both total Akt and phosphorylated Akt remained unchanged. C. Cell viability results presented as the relative cell death ratio. Direct inhibition of PTEN (inhibition of the cytoplasmic function of PTEN) had no influence on the anticancer effect of temozolomide, although inhibition of HOXA10 (indirect inhibition of the nuclear function of PTEN) had an additive anticancer effect with temozolomide in both cell lines.

A

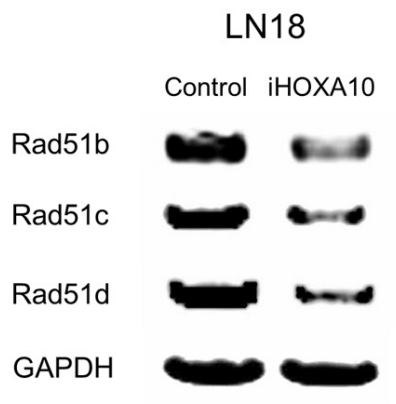

C
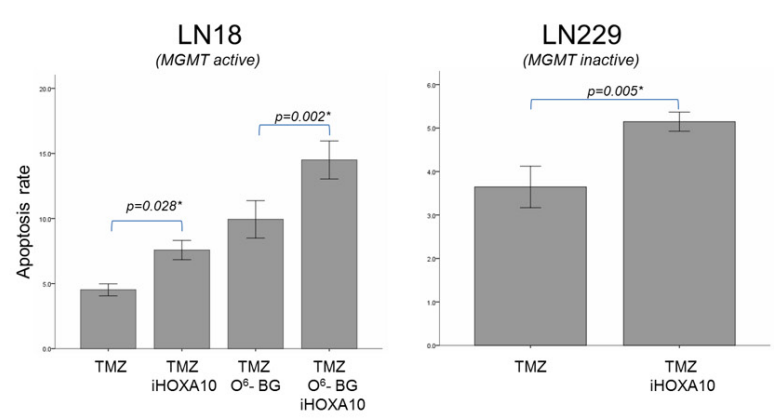

B

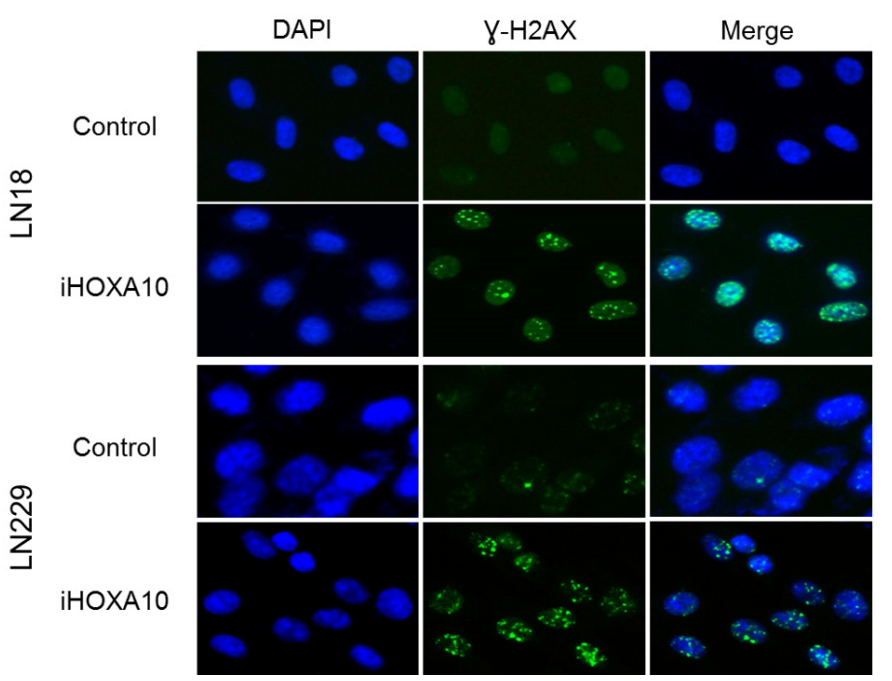

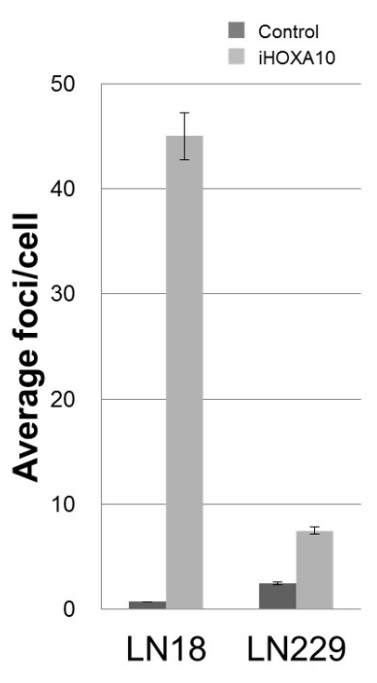

Figure 3: A. RT-PCR results after HOXA10 knockdown by siRNA. Reduced expression of Rad51b, Rad51c, and Rad51d is shown. B. Immunofluorescence image of $\gamma-\mathrm{H} 2 \mathrm{AX}$ foci indicating double-strand DNA breakage. Increased numbers of $\gamma$-H2AX foci are observed with HOXA10 inhibition. C. Annexin V apoptosis assay shows a significant increase in apoptosis in the cancer cell lines by HOXA10 inhibition in combination with temozolomide. 
Table 1: Primers used for PCR amplification.

\begin{tabular}{|l|l|l|l|}
\hline & Forward $\left(5^{\prime} \rightarrow 3^{\prime}\right)$ & Reverse $\left(5^{\prime} \rightarrow 3^{\prime}\right)$ & Amplicon length $(\mathrm{bp})$ \\
\hline HOXA10 & AGGTGGACGCTGCGGCTAATCTCTA & GCCCCTTCCGAGAGCAGCAAAG & 209 \\
\hline EGR1 & CTGCACGCTTCTCAGTGTTCC & CGAGTGAGGAAAGGATCCGA & 210 \\
\hline PTEN & TGGAAAGGGACGAACTGGTG & CACCTTTAGCTGGCAGACCA & 289 \\
\hline Rad51b & TGTGGTGAAACACCCATCGT & TGTTCCACGAACACACAACCCA & 255 \\
\hline Rad51c & TTTGGTGAGTTTCCCGCTGT & ACCCACCCTTAAAAGGAGAACA & 399 \\
\hline Rad51d & GAATGGCGCTGATCTCTACGA & TCTCCTGGAAACCTGTTGGC & 725 \\
\hline GAPDH & GCAGGGGGGAGCCAAAAGGG & TGCCAGCCCCAGCGTCAAAG & 450 \\
\hline
\end{tabular}

only the nuclear function of PTEN without affecting its cytoplasmic function. This finding was also supported by the result of the cell viability test involving inhibition of PTEN directly with siRNA (iPTEN) that suppresses the cytoplasmic function of PTEN. No significant difference in cell death rate was noted whether iPTEN was added or not to TMZ, although significant differences were observed with the IHOXA10 and TMZ combination (Figure 2C).

\section{Impairment of the HR system was observed with HOXA10 inhibition}

We further validated the association of the regulatory activity of HOXA10 with the nuclear function of PTENnamely, the maintenance of the HR system via the positive transcriptional regulation of Rad51 genes. Significant downregulation of all Rad51b, Rad51c, and Rad51d genes was found after HOXA10 knockdown (Figure 3A). Next, the formation of $\gamma-\mathrm{H} 2 \mathrm{AX}$ at the site of double-strand DNA damage was checked. The kinetics of $\gamma-\mathrm{H} 2 \mathrm{AX}$ foci is a well-accepted surrogate marker of the function of the HR system, which repairs DNA-double strand breakage [25]. A significant increase in the number of $\gamma-\mathrm{H} 2 \mathrm{AX}$ foci was demonstrated in iHOXA10-treated cells (Figure 3B), indicating that inhibition of HOXA10 impairs the HR DNA repair system, potentially keeping cancer cells from escaping death after anticancer treatment. The apoptosis assay confirmed that a significantly increased number of cancer cells undergo apoptosis after treatment with both iHOXA10 and temozolomide (Figure 3C).

\section{DISCUSSION}

Homeobox genes are essential developmental regulators, some of which are normally expressed during embryogenesis but are frequently up-regulated in cancer cells [26]. In the normal adult brain, most HOX genes are not expressed at all or are expressed at very low levels [13]. However, reports have demonstrated increased expression of HOX genes in brain tumors as well as other cancers from various organs [16, 26-32]. Murat et al. reported coordinated data of HOX genes and treatment resistance in GBM samples [10]. They found that high HOXA10 expression was predictive of resistance of treatment, including TMZ treatment, independent of the MGMT methylation status of the tumor [10]. The HOX genes aberrantly expressed in cancer cells are considered to be tumor modulators rather than tumor suppressor genes or oncogenes [26]. Recent studies concerning the functional analysis of HOX genes in glioblastoma also corroborate this assertion $[9,18]$. Costa et al. demonstrated that HOXA9 plays oncogenic effects in GBM, such as inhibiting apoptosis and increasing cell proliferation, both of which can be reversed by inhibiting the PI3K pathway through an epigenetic mechanism involving histone H3K27 trimethylation [18]. They also showed that HOXA9 is an independent negative prognostic factor of survival; interestingly, HOXA9 expression remained a valid prognostic factor in the methylated MGMT promoter subgroup [18]. They suggested that the suppression of oncogenic HOXA expression by mTOR- or PI3K-targeted therapies can be a possible anticancer therapy for GBM patients [18]. Gaspar et al. reported a similar study with a more specific focus on treatment resistance [9]. They found high expression levels of the HOXA9/HOXA10 genes in pediatric GBM patient samples as well as a TMZresistant pediatric GBM cell line; high HOXA9/HOXA10 levels were related to shorter survival [9]. Temozolomide resistance in the high HOXA9/HOXA10-expressing GBM cell line was independent of MGMT status, and the PI3K pathway was considered to be an upstream regulator of HOX genes that can be targeted to overcome the resistance [9]. However, neither study investigated the downstream mechanism of temozolomide resistance induced by HOX genes.

In the present study, based on our hypothesis and related experimentation, we confirmed the downstream mechanism of HOXA10 associated with temozolomide resistance. In summary, HOXA10 induces transcription of EGR1, which sequentially results in PTEN expression. PTEN in the nucleus then acts as a positive transcriptional regulator of Rad51 paralogs, which are essential for the maintenance of the HR DNA repair system, which can protect cancer cells from temozolomideinduced cytotoxicity. Thus, inhibition of HOXA10 can downregulate EGR1, PTEN, and Rad51 paralogs in serial 
Table 2: Identification of HOXA10-regulated genes in LN18 cells. HOXA10-silencing siRNA versus control siRNA transduced cells are compared using Affymetrix GeneChip Human Gene 1.0ST Arrays. Probe sets with foldchanges of more than 2-fold are shown (3 up and 54 down probe sets).

\begin{tabular}{|c|c|c|c|c|}
\hline & Gene Accession & Gene Symbol & $\log 2$ ratio (control vs iHOXA10) & Fold change \\
\hline \multicolumn{5}{|c|}{ Up regulation } \\
\hline 1 & NM_001771 & CD22 & 1.37 & 2.58 \\
\hline 2 & NM_001042390 & PTPN20A & 1.38 & 2.60 \\
\hline 3 & NM_001143818 & SERPINB2 & 1.51 & 2.85 \\
\hline \multicolumn{5}{|c|}{ Down regulation } \\
\hline 1 & NM_001166292 & PTCH2 & -1.87 & 3.65 \\
\hline 2 & NR_002979 & SNORA49 & -1.79 & 3.46 \\
\hline 3 & NR_002960 & SNORA20 & -1.79 & 3.45 \\
\hline 4 & NR_003706 & SNORA38B & -1.79 & 3.45 \\
\hline 5 & NR_000018 & SNORD35A & -1.76 & 3.39 \\
\hline 6 & NR_003035 & SNORA16A & -1.71 & 3.28 \\
\hline 7 & NM_014997 & KLHDC10 & -1.06 & 2.08 \\
\hline 8 & NM_015886 & PI15 & -1.69 & 3.23 \\
\hline 9 & NM_032290 & ANKRD32 & -1.65 & 3.15 \\
\hline 10 & NM_001964 & EGR1 & -1.63 & 3.09 \\
\hline 11 & NR_023343 & RNU4ATAC & -1.60 & 3.04 \\
\hline 12 & NR_003137 & RNU4-2 & -1.57 & 2.97 \\
\hline 13 & NR_002963 & SNORA24 & -1.55 & 2.92 \\
\hline 14 & NM_001030 & RPS27 & -1.05 & 2.07 \\
\hline 15 & NR_002911 & SNORA71A & -1.54 & 2.90 \\
\hline 16 & NM_001866 & COX7B & -1.43 & 2.70 \\
\hline 17 & NM_005063 & SCD & -1.43 & 2.70 \\
\hline 18 & NR_003041 & SNORD13 & -1.40 & 2.64 \\
\hline 19 & NR_003041 & SNORD13 & -1.39 & 2.63 \\
\hline 20 & NR_002749 & SNORD45A & -1.37 & 2.58 \\
\hline 21 & NR_002962 & SNORA23 & -1.34 & 2.53 \\
\hline 22 & NR_002447 & SNORD24 & -1.30 & 2.47 \\
\hline 23 & NM_152997 & C4orf7 & -1.28 & 2.43 \\
\hline 24 & NR_000020 & SNORD33 & -1.26 & 2.40 \\
\hline 25 & NR_002748 & SNORD45B & -1.26 & 2.40 \\
\hline 26 & NM_001030 & RPS27 & -1.19 & 2.28 \\
\hline 27 & NR_003018 & SNORA71D & -1.18 & 2.27 \\
\hline 28 & NR_002580 & SNORA3 & -1.18 & 2.26 \\
\hline 29 & NM_004891 & MRPL33 & -1.17 & 2.25 \\
\hline 30 & NR_002569 & SCARNA9 & -1.04 & 2.06 \\
\hline 31 & NM_182511 & CBLN2 & -1.16 & 2.23 \\
\hline 32 & NR_004381 & SNORD105 & -1.14 & 2.21 \\
\hline
\end{tabular}




\begin{tabular}{|l|l|l|l|l|}
\hline 33 & NR_000021 & SNORD32A & -1.14 & 2.21 \\
\hline 34 & NR_000019 & SNORD34 & -1.14 & 2.20 \\
\hline 35 & NR_003002 & SCARNA13 & -1.14 & 2.20 \\
\hline 36 & NM_019058 & DDIT4 & -1.12 & 2.17 \\
\hline 37 & NR_003017 & SNORA71C & -1.12 & 2.17 \\
\hline 38 & NM_006111 & ACAA2 & -1.11 & 2.16 \\
\hline 39 & NR_000024 & SNORD46 & -1.11 & 2.15 \\
\hline 40 & NR_004380 & SNORD104 & -1.10 & 2.15 \\
\hline 41 & NM_000599 & IGFBP5 & -1.09 & 2.14 \\
\hline 42 & NR_002450 & SNORD68 & -1.09 & 2.13 \\
\hline 43 & NM_001030 & RPS27 & -1.09 & 2.12 \\
\hline 44 & NR_029707 & MIR186 & -1.08 & 2.12 \\
\hline 45 & NR_002922 & SNORA13 & -1.08 & 2.11 \\
\hline 46 & NR_000012 & SNORA68 & -1.07 & 2.10 \\
\hline 47 & NM_001170423 & PRSS35 & -1.07 & 2.10 \\
\hline 48 & NM_001030 & RPS27 & -1.07 & 2.10 \\
\hline 49 & NR_002961 & SNORA22 & -3.50 & 11.32 \\
\hline 50 & NR_002751 & SNORD41 & -2.93 & 7.63 \\
\hline 51 & NM_020299 & AKR1B10 & -2.41 & 5.31 \\
\hline 52 & NR_003925 & RNU4-1 & -2.02 & 4.05 \\
\hline 53 & NR_002753 & RNU5F & -1.89 & 2.71 \\
\hline 54 & NM_016097 & IER3IP1 & -1.07 & \\
\hline
\end{tabular}

order to interfere with the HR system of cancer cells, making the cancer cell more vulnerable to temozolomide treatment. These processes occur at the nuclear level, and thus, the inhibition of HOXA10 does not affect the tumor suppressor function of PTEN that occurs in the cytoplasm. Studies have proposed novel nuclear functions of PTEN, including transcription regulation, other than its classical role of repressing the PI3K/Akt pathway [23, 24, 33]. McEllin et al. have also shown that PTEN has a novel nuclear function of transcriptional regulation of the Rad51 gene [4]. They also mentioned that downregulation of HR due to PTEN loss would result in sensitivity to DNA alkylating agents or PARP inhibitors [4]. The role of EGR1 as a mediator of PTEN regulation has been proposed in multiple studies $[20-22,34]$. The PTEN pathway is regulated at multiple different levels. Among them, p53, IGF2, PPAR $\gamma$, and EGR1 are molecules that can directly act on the promoter of PTEN to activate transcription [35]. Taken together, all the above lines of evidence, including our results, support the integrity of the EGR1-PTEN-Rad51 axis for HR system regulation initiated by HOXA10.

TMZ has been reported to be a strong double-strand
DNA break inducer with a potency more than 10 -fold that of ionizing radiation [36]. Although studies have indicated that molecules comprising the HR system can be potential modulators of temozolomide cytotoxicity, the importance of the HR system for temozolomide resistance was not highlighted until recently [37-44]. Therefore, the status of HR system in cancer cells may likely be used a biomarker or target to determine the clinical response to TMZ treatment. Moreover, it is also important to consider the MGMT status together with the HR system status because the concepts of oncogenic addiction and synthetic lethality can be applied [45]. For example, the possibility exists for the augmentation of MMR and the HR system in cancer cells with MGMT in an inactive state, such as in GBM with a methylated MGMT promoter, which has potential to interfere with TMZ cytotoxicity. In that case, inhibition of the HR system itself may show an enhanced anticancer effect through sensitization to TMZ treatment. Our study indicates that the HOXA10 can be a good therapeutic target as well as a biomarker to overcome TMZ resistance in the management of GBM patients. 


\section{MATERIALS AND METHODS}

\section{Cell lines}

The human glioma LN18 and LN229 cell lines were obtained and cultured in DMEM containing 10\% fetal bovine serum and 5\% antibiotics (streptomycin) in a humidified atmosphere of $5 \% \mathrm{CO}_{2}$ and $95 \%$ air at $37^{\circ} \mathrm{C}$. Both cell lines express wild-type phosphatase and tensin homolog (PTEN) as described previously [46]. We performed methylation-specific polymerase chain reaction (MSP) to confirm the methylation status of the MGMT promoter after DNA isolation and bisulfite treatment in these cell lines as described previously [47].

\section{mRNA expression}

The primers used were designed using the primerBLAST tool available on-line (http://www.ncbi.nlm. nih.gov/tools/primer-blast/). The primer sequence of HOXA10, EGR1, PTEN, Rad51b, Rad51c, Rad51d, and GAPDH are summarized (Table 1). Using these primers, reverse transcription-polymerase chain reaction (RTPCR) was performed to evaluate their expression. Cell lines were lysed with TRIzol (Life technologies), and RNA isolation was performed using an RNeasy Mini Kit (QIAGEN, \#74104). Total RNA was treated with DNase and then quantified by spectrophotometry. Additionally, cDNA was synthesized from $1 \mu \mathrm{g}$ of total RNA using a reverse transcription kit (QIAGEN, \#205311) according to the manufacturer's procedure. The RT-PCR reaction was carried out for 35 cycles, comprising $95^{\circ} \mathrm{C}$ for $5 \mathrm{~min}$, $95^{\circ} \mathrm{C}$ for $30 \mathrm{sec}$, and $58^{\circ} \mathrm{C}$ for $30 \mathrm{sec}$ with each primer set. RT-PCR products were resolved by $2 \%$ agarose gel electrophoresis, and the bands were quantified using image analyzing software (ImageJ v1.47; http://rsb.info.nih.gov/ ij/).

\section{RNA interference}

For small interfering RNA (siRNA) experiments, commercially available sequences targeting HOXA10 (iHOX; Sigma Aldrich, \#SASI_Hs01_00172491) and PTEN (iPTEN; Dharmacon, \#L-003023-00-0005) as well as nontargeting control siRNAs (Dharmacon, \#D-00161001-05) were used. At 70-80\% confluence, the cells were transfected with siRNAs at the most efficient transfection condition determined by the NEON ${ }^{\circledR}$ Transfection system (Life Technologies, \#MPK5000). The cells were cultured in media without antibiotics to increase the siRNA transfection efficiency for 24 hours.

\section{Drug treatment and cell viability analysis}

Normal and transfected cells were grown on 96-well plates at a density of $4 \times 10^{3}$ cells per well for 24 hours. Temozolomide (TMZ; Enzo, \#420-044-M100) and $\mathrm{O}^{6}$ benzylguanine (O6-BG; Sigma Aldrich, \#B2292-50MG) were treated with a final concentration of $1000 \mu \mathrm{g} / \mathrm{ml}$ and $300 \mu \mathrm{g} / \mathrm{ml}$ for 24 hours, respectively. Cell viability analysis was performed using a Colorimetric Cell Counting kit-8 (CCK; Dojindo Molecular Technologies). Quantification of viable cells was performed by the reading of ultraviolet (UV) absorption spectra at $450 \mathrm{~nm}$ on a microplate 2 hours after adding $10 \mu \mathrm{l}$ of CCK solution per well according to the manufacturer's instructions. All experiments were conducted in triplicate.

\section{Gene expression profiling}

Samples of the LN18 cell line transduced with siHOXA10 as well as control siRNA for 24 hours were analyzed using Affymetrix GeneChip Human Gene 1.0ST Arrays (Affymetrix) to identify the gene expression changes before and after HOXA10 knockdown. Expression data were normalized using the robust multiarray average (RMA) method. Affymetrix Expression Console Version 1.1 (Affymetrix) was used to compare the group signals, and data were log-transformed (base 2 ) for parametric analysis. Differentially expressed genes were identified using significance analysis of microarrays (SAM) with the R package 'samr' (R 2.11.1).

\section{Protein detection}

Whole protein extracts of the cells for western blotting were prepared using PRO-PREP lysis buffer (Intron, \#17081), and protein concentrations were determined using the BCA protein assay (Thermo Fisher Scientific, \#23227). Proteins were separated by $10 \%$ SDS-PAGE, blotted onto nitrocellulose membranes, and then probed with antibodies against total AKT (Genetex, \#GTX121937, 1:3000 dilution), phosphorylated AKT (Genetex \#GTX61708, 1:2000 dilution), total PTEN (Genetex, \#GTX101025, 1:500 dilution), and phosphorylated PTEN (Genetex, \#GTX61780, 1:1000 dilution). The membranes were then incubated with a goat anti-rabbit IgG secondary antibody (Jackson, \#003318367, 1:4000 dilution) for 1 hour. The membranes were incubated in ECL-prime solution (GE Healthcare Amersham, \#RPN2232) in the dark for 1 minute and then exposed under a fluorchemHD2 (Cell biosciences) for visualization. 


\section{DNA double-strand break assay}

The DNA double-strand break (DSB) rates were assessed by quantifying the rates of $\gamma$-H2AX foci. Approximately $5 \times 10^{4}$ cells were seeded on coverslips after drug treatment and were cultured overnight in a $37 \square$ incubator without antibiotics. The following day, cells were fixed with $100 \%$ cold methanol for 5 minutes and then permeabilized with $0.25 \%$ PBST for 20 minutes. Next, the cells were incubated in 5\% skim milk to block non-specific protein-protein interactions and immunostained with a $\gamma-\mathrm{H} 2 \mathrm{AX}$ primary antibody (Abcam, \#ab22551) and an FITC-conjugated rabbit antimouse secondary antibody (Invitrogen, \#A11029). The number of $\gamma-\mathrm{H} 2 \mathrm{AX}$ foci with DAPI was determined using a fluorescence microscope (100× objective). Disrupted cells were excluded from the analysis. Foci counting was performed for an average of 50 cells. The mean number of foci per cell was scored, and the standard error of the mean was calculated.

\section{Apoptosis assay}

For apoptosis assays, cells were harvested and suspended in annexin V-binding buffer (BD Biosciences, \#556570) at a concentration of $1 \times 10^{5}$ cells/100 $\mu$ l. Next, $5 \mu 1$ of annexin V-FITC and $5 \mu 1$ of propidium iodide (PI) were added to each sample, and the samples were incubated in the dark at room temperature for $15 \mathrm{~min}$. The samples were run through a FACScan flow cytometer (BD-FACSCalibur-2, \#633488), and annexin V positive and PI negative cells were designated apoptotic.

\section{Statistical analysis}

ANOVA and Student's $t$ test were used to identify significant differences in the cell death rate, DSB assay, and apoptosis experiments. The results were analyzed using IBM SPSS Statistics software (version 19.0; SPSS, Inc.). Data are presented as the mean \pm standard deviation (SD) of three or more separate experiments, and a $\mathrm{P}$ value of 0.05 was considered to be statistically significant.

\section{ACKNOWLEDGMENTS}

This research was supported by the Basic Science Research Program through the National Research Foundation of Korea (NRF) funded by the Ministry of Education, Science and Technology (2012R1A1A2003779) and by a grant from the Seoul National University Research Fund (800-20130069).

\section{REFERENCES}

1. Stupp R, Hegi ME, Mason WP, van den Bent MJ, Taphoorn MJ, Janzer RC, Ludwin SK, Allgeier A, Fisher B, Belanger K, Hau P, Brandes AA, Gijtenbeek J, Marosi C, Vecht CJ, Mokhtari K, et al. Effects of radiotherapy with concomitant and adjuvant temozolomide versus radiotherapy alone on survival in glioblastoma in a randomised phase III study: 5-year analysis of the EORTC-NCIC trial. Lancet Oncol. 2009; 10(5):459-466.

2. Hegi ME, Diserens AC, Gorlia T, Hamou MF, de Tribolet N, Weller M, Kros JM, Hainfellner JA, Mason W, Mariani L, Bromberg JE, Hau P, Mirimanoff RO, Cairncross JG, Janzer RC and Stupp R. MGMT gene silencing and benefit from temozolomide in glioblastoma. N Engl J Med. 2005; 352(10):997-1003.

3. Park CK, Kim JE, Kim JY, Song SW, Kim JW, Choi SH, Kim TM, Lee SH, Kim IH and Park SH. The Changes in MGMT Promoter Methylation Status in Initial and Recurrent Glioblastomas. Transl Oncol. 2012; 5(5):393397.

4. McEllin B, Camacho CV, Mukherjee B, Hahm B, Tomimatsu N, Bachoo RM and Burma S. PTEN loss compromises homologous recombination repair in astrocytes: implications for glioblastoma therapy with temozolomide or poly(ADP-ribose) polymerase inhibitors. Cancer research. 2010; 70(13):5457-5464.

5. Zhang J, Stevens MF and Bradshaw TD. Temozolomide: mechanisms of action, repair and resistance. Curr Mol Pharmacol. 2012; 5(1):102-114.

6. Yip S, Miao J, Cahill DP, Iafrate AJ, Aldape K, Nutt CL and Louis DN. MSH6 mutations arise in glioblastomas during temozolomide therapy and mediate temozolomide resistance. Clin Cancer Res. 2009; 15(14):4622-4629.

7. Cahill DP, Levine KK, Betensky RA, Codd PJ, Romany CA, Reavie LB, Batchelor TT, Futreal PA, Stratton MR, Curry WT, Iafrate AJ and Louis DN. Loss of the mismatch repair protein MSH6 in human glioblastomas is associated with tumor progression during temozolomide treatment. Clin Cancer Res. 2007; 13(7):2038-2045.

8. Hunter C, Smith R, Cahill DP, Stephens P, Stevens C, Teague J, Greenman C, Edkins S, Bignell G, Davies H, O'Meara S, Parker A, Avis T, Barthorpe S, Brackenbury L, Buck G, et al. A hypermutation phenotype and somatic MSH6 mutations in recurrent human malignant gliomas after alkylator chemotherapy. Cancer research. 2006; 66(8):3987-3991.

9. Gaspar N, Marshall L, Perryman L, Bax DA, Little SE, Viana-Pereira M, Sharp SY, Vassal G, Pearson AD, Reis RM, Hargrave D, Workman P and Jones C. MGMTindependent temozolomide resistance in pediatric glioblastoma cells associated with a PI3-kinase-mediated $\mathrm{HOX} / \mathrm{stem}$ cell gene signature. Cancer Res. 2010; 70(22):9243-9252.

10. Murat A, Migliavacca E, Gorlia T, Lambiv WL, 
Shay T, Hamou MF, de Tribolet N, Regli L, Wick W, Kouwenhoven MC, Hainfellner JA, Heppner FL, Dietrich PY, Zimmer Y, Cairncross JG, Janzer RC, et al. Stem cellrelated "self-renewal" signature and high epidermal growth factor receptor expression associated with resistance to concomitant chemoradiotherapy in glioblastoma. J Clin Oncol. 2008; 26(18):3015-3024.

11. Ohgo S, Itoh A, Suzuki M, Satoh A, Yokoyama H and Tamura K. Analysis of hoxa11 and hoxa13 expression during patternless limb regeneration in Xenopus. Developmental biology. 2010; 338(2):148-157.

12. Hueber SD and Lohmann I. Shaping segments: Hox gene function in the genomic age. BioEssays : news and reviews in molecular, cellular and developmental biology. 2008; 30(10):965-979.

13. Takahashi Y, Hamada J, Murakawa K, Takada M, Tada M, Nogami I, Hayashi N, Nakamori S, Monden M, Miyamoto M, Katoh $\mathrm{H}$ and Moriuchi T. Expression profiles of 39 HOX genes in normal human adult organs and anaplastic thyroid cancer cell lines by quantitative real-time RT-PCR system. Exp Cell Res. 2004; 293(1):144-153.

14. Henderson GS, van Diest PJ, Burger H, Russo J and Raman V. Expression pattern of a homeotic gene, HOXA5, in normal breast and in breast tumors. Cell Oncol. 2006; 28(56):305-313.

15. Yuan W, Zhang X, Xu Y, Li S, Hu Y and Wu S. Role of HOXB7 in regulation of progression and metastasis of human lung adenocarcinoma. Molecular carcinogenesis. 2012.

16. Abdel-Fattah R, Xiao A, Bomgardner D, Pease CS, Lopes $\mathrm{MB}$ and Hussaini IM. Differential expression of HOX genes in neoplastic and non-neoplastic human astrocytes. J Pathol. 2006; 209(1):15-24.

17. Buccoliero AM, Castiglione F, Degl'Innocenti DR, Ammanati F, Giordano F, Sanzo M, Mussa F, Genitori L and Taddei GL. Hox-D genes expression in pediatric lowgrade gliomas: real-time-PCR study. Cell Mol Neurobiol. 2009; 29(1):1-6.

18. Costa BM, Smith JS, Chen Y, Chen J, Phillips HS, Aldape KD, Zardo G, Nigro J, James CD, Fridlyand J, Reis RM and Costello JF. Reversing HOXA9 oncogene activation by PI3K inhibition: epigenetic mechanism and prognostic significance in human glioblastoma. Cancer Res. 2010; 70(2):453-462.

19. Huang da W, Sherman BT and Lempicki RA. Systematic and integrative analysis of large gene lists using DAVID bioinformatics resources. Nature protocols. 2009; 4(1):4457.

20. Su L, Cheng H, Sampaio AV, Nielsen TO and Underhill TM. EGR1 reactivation by histone deacetylase inhibitors promotes synovial sarcoma cell death through the PTEN tumor suppressor. Oncogene. 2010; 29(30):4352-4361.

21. Lau MT, Klausen C and Leung PC. E-cadherin inhibits tumor cell growth by suppressing PI3K/Akt signaling via
beta-catenin-Egr1-mediated PTEN expression. Oncogene. 2011; 30(24):2753-2766.

22. Yu J, Zhang SS, Saito K, Williams S, Arimura Y, Ma Y, Ke Y, Baron V, Mercola D, Feng GS, Adamson E and Mustelin T. PTEN regulation by Akt-EGR1-ARF-PTEN axis. The EMBO journal. 2009; 28(1):21-33.

23. Shen WH, Balajee AS, Wang J, Wu H, Eng C, Pandolfi PP and Yin Y. Essential role for nuclear PTEN in maintaining chromosomal integrity. Cell. 2007; 128(1):157-170.

24. Yin Y and Shen WH. PTEN: a new guardian of the genome. Oncogene. 2008; 27(41):5443-5453.

25. Rogakou EP, Pilch DR, Orr AH, Ivanova VS and Bonner WM. DNA double-stranded breaks induce histone H2AX phosphorylation on serine 139. The Journal of biological chemistry. 1998; 273(10):5858-5868.

26. Abate-Shen C. Deregulated homeobox gene expression in cancer: cause or consequence? Nat Rev Cancer. 2002; 2(10):777-785.

27. Bodey B, Bodey B, Jr., Siegel SE and Kaiser HE. Immunocytochemical detection of the homeobox B3, B4, and C6 gene products in childhood medulloblastomas/ primitive neuroectodermal tumors. Anticancer Res. 2000; 20(3A):1769-1780.

28. Buccoliero AM, Castiglione F, Rossi Degl'Innocenti D, Ammanati F, Giordano F, Sanzo M, Mussa F, Genitori L and Taddei GL. Hox-D genes expression in pediatric lowgrade gliomas: real-time-PCR study. Cellular and molecular neurobiology. 2009; 29(1):1-6.

29. Argiropoulos B and Humphries RK. Hox genes in hematopoiesis and leukemogenesis. Oncogene. 2007; 26(47):6766-6776.

30. Cillo C, Barba P, Freschi G, Bucciarelli G, Magli MC and Boncinelli E. HOX gene expression in normal and neoplastic human kidney. International journal of cancer Journal international du cancer. 1992; 51(6):892-897.

31. De Vita G, Barba P, Odartchenko N, Givel JC, Freschi G, Bucciarelli G, Magli MC, Boncinelli E and Cillo C. Expression of homeobox-containing genes in primary and metastatic colorectal cancer. European journal of cancer. 1993; 29A(6):887-893.

32. Bahrani-Mostafavi Z, Tickle TL, Zhang J, Bennett KE, Vachris JC, Spencer MD, Mostafavi MT and Tait DL. Correlation analysis of HOX, ErbB and IGFBP family gene expression in ovarian cancer. Cancer Invest. 2008; 26(10):990-998.

33. Salmena L, Carracedo A and Pandolfi PP. Tenets of PTEN tumor suppression. Cell. 2008; 133(3):403-414.

34. Sarver AL, Li L and Subramanian S. MicroRNA miR-183 functions as an oncogene by targeting the transcription factor EGR1 and promoting tumor cell migration. Cancer research. 2010; 70(23):9570-9580.

35. Zhang S and Yu D. PI(3)king apart PTEN's role in cancer. Clin Cancer Res. 2010; 16(17):4325-4330.

36. Helleday T. Homologous recombination in cancer 
development, treatment and development of drug resistance. Carcinogenesis. 2010; 31(6):955-960.

37. Knizhnik AV, Roos WP, Nikolova T, Quiros S, Tomaszowski KH, Christmann M and Kaina B. Survival and death strategies in glioma cells: autophagy, senescence and apoptosis triggered by a single type of temozolomideinduced DNA damage. PloS one. 2013; 8(1):e55665.

38. Eich M, Roos WP, Dianov GL, Digweed M and Kaina B. Nijmegen breakage syndrome protein $(\mathrm{NBN})$ causes resistance to methylating anticancer drugs such as temozolomide. Molecular pharmacology. 2010; 78(5):943951.

39. Quiros S, Roos WP and Kaina B. Rad51 and BRCA2--New molecular targets for sensitizing glioma cells to alkylating anticancer drugs. PloS one. 2011; 6(11):e27183.

40. Short SC, Giampieri S, Worku M, Alcaide-German M, Sioftanos G, Bourne S, Lio KI, Shaked-Rabi M and Martindale C. Rad51 inhibition is an effective means of targeting DNA repair in glioma models and CD133+ tumorderived cells. Neuro-oncology. 2011; 13(5):487-499.

41. Caporali S, Falcinelli S, Starace G, Russo MT, Bonmassar E, Jiricny $J$ and D'Atri S. DNA damage induced by temozolomide signals to both ATM and ATR: role of the mismatch repair system. Molecular pharmacology. 2004; 66(3):478-491.

42. Stojic L, Mojas N, Cejka P, Di Pietro M, Ferrari S, Marra G and Jiricny J. Mismatch repair-dependent G2 checkpoint induced by low doses of SN1 type methylating agents requires the ATR kinase. Genes \& development. 2004; 18(11):1331-1344.

43. Mirzoeva OK, Kawaguchi T and Pieper RO. The Mre11/ Rad50/Nbs1 complex interacts with the mismatch repair system and contributes to temozolomide-induced G2 arrest and cytotoxicity. Molecular cancer therapeutics. 2006; 5(11):2757-2766.

44. Schroering AG, Kothandapani A, Patrick SM, Kaliyaperumal S, Sharma VP and Williams KJ. Prolonged cell cycle response of HeLa cells to low-level alkylation exposure. Cancer research. 2009; 69(15):6307-6314.

45. Kaelin WG, Jr. The concept of synthetic lethality in the context of anticancer therapy. Nature reviews Cancer. 2005; 5(9):689-698.

46. Wick W, Furnari FB, Naumann U, Cavenee WK and Weller M. PTEN gene transfer in human malignant glioma: sensitization to irradiation and CD95L-induced apoptosis. Oncogene. 1999; 18(27):3936-3943.

47. Park CK, Kim J, Yim SY, Lee AR, Han JH, Kim CY, Park SH, Kim TM, Lee SH, Choi SH, Kim SK, Kim DG and Jung HW. Usefulness of MS-MLPA for detection of MGMT promoter methylation in the evaluation of pseudoprogression in glioblastoma patients. Neurooncology. 2011; 13(2):195-202. 